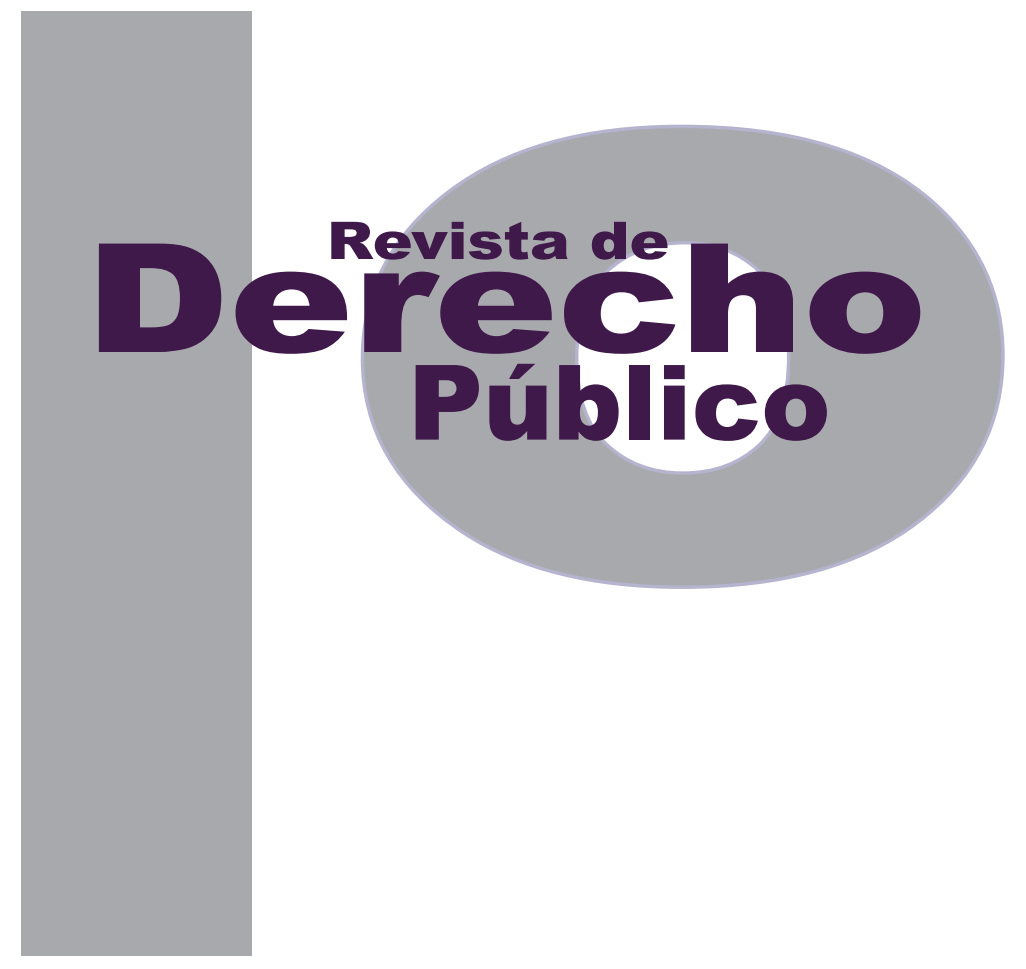

\title{
LA COMPETENCIA INTERNACIONAL DE LA CPI Y LOS FACTORES DE RESPONSABILIDAD EN EL CASO COLOMBIANO
}

Jaime Alberto Sandoval Mesa

Universidad de los Andes

Facultad de Derecho

Revista de Derecho Público N. ${ }^{\circ} 31$

Julio - Diciembre de 2013. ISSN 1909-7778 


\title{
La competencia internacional de la CPI y los factores de responsabilidad en el caso colombiano*
}

\author{
Jaime Alberto Sandoval Mesa**
}

\section{RESUMEN}

El presente documento versa sobre el alcance de los factores de competencia de la Corte Penal Internacional (CPI), en primer lugar, desde sus fundamentos concebidos en el desarrollo de los instrumentos de protección de los derechos humanos y del derecho internacional humanitario (DIH), así como desde los desarrollos de la justicia internacional. En segundo término se verifican los fundamentos para la construcción de la justicia internacional desde los desarrollos del Estatuto de Roma de 1998 para la creación de la CPI tanto a nivel internacional como su in-
This paper focuses on the scope of the factors jurisdiction of the ICc, first designed from the ground in the development of instruments for the protection of human rights and IHL, as well as from the development of international justice. Secondly, we verified the basics for building international justice from the developments of the 1998 Rome Statute for the creation of the ICC both internationally and domestically incorporation. Finally, determine the scope of international justice with regard to competitive factors

Cómo citar este artículo: Sandoval Mesa, J. A. (Diciembre, 2013). La competencia internacional de la CPI y los factores de responsabilidad en el caso colombiano. Revista de Derecho Público, 31. 
corporación a nivel interno. Finalmente se determinan los alcances de la justicia internacional con respecto a los factores de competencia y su interés en el caso colombiano, así como su posible actuación en virtud de la responsabilidad internacional en el contexto nacional.

PALABRAS CLAVE: instrumentos internacionales, derechos humanos, crímenes internacionales, competencia, factores, situación, caso concreto, responsabilidad, justicia penal internacional. and interest in the case of Colombia, as well as its possible action under international responsibility in the national context.

KEY WORDS: international instruments, human rights, international crimes, jurisdiction, factors, situation, case, responsibility, international criminal justice.. 


\section{SUMARIO}

Introducción - I. DESARROLLOS CONCRETOS DE LAS BASES INTERNACIONALES QUE CONFIGURAN LA JUSTICIA INTERNACIONAL - A. Los avances desde el principio de justicia universal frente a la justicia internacional - II. LA CONSTRUCCIÓN DE LA COMPETENCIA INTERNACIONAL EN LA CPI - A. Principales elementos cronológicos en la formación de la CPI - B. Desarrollo de la CPI en el derecho interno (del proyecto de acto legislativo 02 de 2001 a la Ley 742 del 5 de junio de 2002) - III. FACTORES DE COMPETENCIA DEL ESTATUTO DE ROMA Y ADMISIBILIDAD - A. Factor ratione temporis - $B$. Factor ratione personae. Subjetivo - $C$. Factor ratione materiae. Los crímenes de competencia de la $C P I$ - 1. Genocidio - 2. Crímenes de lesa humanidad - 3. Crímenes de guerra - 4. De agresión IV. LOS FACTORES CONCRETOS EN LA SITUACIÓN COLOMBIANA - V. CONCLUSIONES - Bibliografía. 


\section{Introducción}

En la doctrina actual de los derechos humanos y del derecho internacional humanitario, la generación de una competencia universal ha tenido que conciliar los intereses que desde los extremos de estas dos corrientes han dado paso al establecimiento de los atentados de lesa humanidad.

Por un lado, el derecho de los derechos humanos se basa en casi 200 instrumentos que le sirven de fuente, en tanto que el $\mathrm{DIH}$ ha sido recogido en prácticamente 21 documentos internacionales. Los sujetos destinatarios de los primeros están constituidos únicamente por los Estados, mientras que en el DIH se incluye tanto a los Estados como a las altas partes contratantes de los cuatro convenios de Ginebra de 1949 y de los protocolos adicionales de 1977 , así como a las partes envueltas en conflictos armados de carácter interno o internacional. Este proceso de desarrollo de instrumentos internacionales de protección tuvo un gran respaldo luego de los juicios de Nüremberg, si se tiene en cuenta el análisis de las graves violaciones que se presentaron en el escenario de los conflictos armados y, sobre todo, el haber partido la historia en la protección de los derechos humanos al considerar no solo la gravedad de las violaciones sino al elevarlas a la condición de crímenes internacionales.

Bajo esta preceptiva, es preciso resaltar que el derecho de los derechos humanos posee un completo sistema de protección universal y regional, que permite que los Estados responsables de violaciones a tales derechos sean objeto de sanción, así como de la obligación de hacer cesar el acto violatorio y de reparar los daños causados o, cuando no es posible restablecer el derecho violado, de indemnizar a las víctimas de estas violaciones (Córdoba, 2001, p. 28). En contraposición, el derecho internacional humanitario carece de este sistema de protección por lo que debe remitirse a la voluntad de los Estados para su cumplimiento. No obstante, por ejemplo, muchas de las graves infracciones deben ser desarrolladas en el derecho penal interno para asegurar su eficaz protección, es decir, puede generarse otra afectación al principio penal interno por la asunción de instrumentos de esta naturaleza.

De otra parte, el derecho de los derechos humanos protege a la persona humana en general, en tanto que el DIH protege a los combatientes y a los no combatientes, con diferencias en los tipos y grados de protección, pero siempre dentro del marco de un conflicto armado interno o internacional. Precisamente, sobre esta línea, los atentados de lesa humanidad y su correspondencia, bien con el derecho de los derechos humanos, o bien con el DIH, se han tenido que definir a partir de instrumentos que en medio del conflicto entre guerra y paz, desde 1948 han sentado las bases para el establecimiento de una jurisdicción universal destinada a su privilegiada atención. E incluso este factor en la actualidad cobra mayor vigencia por la ineludible relación sistema internacional de protección de derechos humanos, sistema penal interno, en donde todas estas afectaciones se resuelven mediante la interpretación del principio de legalidad penal. 
Fruto de esta evolución en el marco internacional, en la actualidad el mayor desarrollo de protección de la justicia internacional reside en el establecimiento de la cPI, como el mecanismo idóneo para que a través de esta jurisdicción universal se sinteticen las posibilidades reales de ejercicio y aplicación de los principios derivados tanto del DIH como del derecho de los derechos humanos. Además, este umbral de lo que es absolutamente condenable para todos, de lo que no puede dejar de ser aceptado, de lo que es absolutamente inviolable, sin duda ejerce presión en el sistema penal interno, más si se tienen en cuenta escenarios de conflicto armado en donde las más graves conductas punitivas internacionales puedan presentarse. ${ }^{1}$

\section{DESARROLLOS CONCRETOS DE LAS BASES INTERNACIONALES QUE CONFIGURAN LA JUSTICIA INTERNA- CIONAL}

De acuerdo con lo anterior es posible inferir que en los dos sistemas jurídicos universales de protección de derechos humanos - derecho internacional de los derechos humanos y $\mathrm{DH}-$ se establecen principios relacionados tanto con las garantías y debido proceso como con el nuIlum crimen sine lege y contenido material de las conductas, desde el ámbito de lesión colectivo de bienes jurídicos (art. $3^{\circ}$ común a los cuatro convenios de Ginebra de 1949; 0`Donnell, 2004, p. 381).

1 Intervención del Defensor del Pueblo en la Revisión de constitucionalidad de la Ley 742 del 5 de junio de 2002. Corte Constitucional, sentencia C-578-02 del 30 de julio de 2002.
Así mismo, en el seno de la Declaración Universal de los Derechos Humanos (1948) -en adelante DUDH-, se encuentra el debido proceso como principio y presupuesto en contra de las torturas, penas o tratos crueles, inhumanos o degradantes (art. 5 DUDH). En ella se promulgan y reafirman los principios y garantías que deben primar en la justicia, como la igualdad ante la ley (art. 7), presunción de inocencia (art. 11.1) y el principio de legalidad (arts. 10 y 11.2) que aparece descrito en los siguientes términos:

Artículo 11.2. Nadie será condenado por actos $\mathrm{u}$ omisiones que en el momento de cometerse no fueron delictivos según el Derecho nacional o internacional. Tampoco se impondrá pena más grave que la aplicable en el momento de la comisión del delito.

Como podrán ver, aquí se reitera la imposibilidad de juzgar conductas que no se encuentren conforme al derecho nacional o internacional, mientras que los estatutos internos hacen parte del derecho de cada Estado. No obstante, en este principio se permite la definición de conductas según el derecho internacional, con lo cual se amplía el radio de protección no solo en el contexto legal interno, sino también en el internacional. Así mismo, el anterior principio se reitera en instrumentos como el Pacto Internacional de Derechos Civiles y Políticos de 1966 en el cual comienzan a aparecer elementos de influencia internacional en materia penal. Todo lo anterior, sumado a los precedentes de los tribunales penales internacionales, sin oposición, tiene relevancia en el derecho penal interno, en las bases del sistema actual y en los factores 
objeto de revisión por parte de la justicia internacional en el derecho interno.

\section{A. Los avances desde el principio de justicia universal frente a la justicia internacional}

Otro factor que ha permitido identificar la influencia de la justicia internacional y su intervención en el sistema penal interno se desarrolló bajo los elementos del principio de jurisdicción universal, que en los estatutos nacionales otorgaba a los tribunales de cualquier país la competencia para sancionar crímenes internacionales, como por ejemplo crímenes de lesa humanidad, crímenes de guerra y genocidio, independientemente del territorio donde se hubiere cometido el hecho y la nacionalidad del perpetrador o de la víctima (Riedmatten, 2005).

En todo caso esta concepción era limitada en la medida en que debía proceder si el Estado requerido aceptaba esta competencia. Si no la aceptaba sus resultados no eran relevantes, sin embargo este principio también permitió asegurar las bases de la justicia internacional, así como sus primeros pasos hacia la intervención en el derecho penal interno.

Este concepto, hasta la aparición del Estatuto de Roma (ER) de 1998 y su entrada en vigencia en el año 2001, era posible en algunas legislaciones como la española para la persecución de crímenes internacionales, por ejemplo, el caso adelantado en el año de 1998, en el cual la audiencia nacional procedió por los delitos de genocidio y terrorismo que se imputaban por la jurisdicción española al Sr. Adolfo Francisco Scilingo y otros, cometidos entre 1976 y 1983, durante la dictadura en Argentina. En estos casos, sin duda, se observan decisiones trascendentes con respecto a la jurisdicción interna, en términos más de interés de justicia material. (Audiencia Nacional. Sala de lo Penal. Sección Tercera. Sumario 19/97. Juzgado Central de Instrucción Número Cinco. Madrid, España, M. P. D. Francisco Castro Meije et al. Decisión de 4 de noviembre de 1998).

Este principio, en el caso español, ha sufrido reformas como la del año 2009 que han limitado sus efectos actuales (Ley Orgánica 1/2009, art. 23.4. Ley Orgánica del Poder Judicial).

Pues bien, en torno a esta idea se han plasmado a lo largo de la historia las bases de un principio internacional de justicia reclamado en diversas formas, como por ejemplo, mediante el denominado principio universal. En virtud de este, según la ley penal de un Estado, como por ejemplo el español, es aplicable respecto de determinados delitos, con independencia del lugar de su comisión y de la nacionalidad del delincuente. Se trata de un principio complementario del de territorialidad cuya finalidad última es impedir la impunidad del delincuente. ${ }^{2}$

Así mismo, el presupuesto fundamental para la aplicación de la ley penal en virtud de este principio, en España, corresponde a la naturaleza o el carácter de los delitos sometidos a dicho principio. En efecto, se trataba de delitos que

2 Cfr. LOPJ, art. 23.4, modificado por: Ley orgánica 3 de 8 de julio de 2005; LOPJ 1/2009, art. 23.4). 
atentaran no contra valores estatales o individuales sino contra intereses fundamentales de la comunidad internacional, intereses transcendentales y en cuya conservación estuviere interesada la comunidad internacional como un todo (Andrés, 2006, p. 177).

En el mismo sentido, otro concepto señala que el criterio de la jurisdicción universal permite la persecución de actos que vulneran directamente valores e intereses comunitarios (Sánchez, 2004, pp. 37 y 38). Es decir, se destacan preocupaciones relevantes en materia de persecución de crímenes no solo de trascendencia internacional, sino también de hechos actualmente impunes. En este orden, la preocupación gira en torno a la justicia material, con los obstáculos y dificultades que se generan al no contar con límites más flexibles de la legalidad penal. En último término, estos valores se resumen en la lucha contra la impunidad internacional que es el objeto principal de la jurisdicción universal.

En criterio de Zaffaroni (2001, pp. 53 y 54) este fenómeno de la impunidad se caracteriza por etapas de comisión de los crímenes, en donde el poder de contención judicial de la violencia criminal estatal siempre está reducido a la impotencia. Según su opinión, los crímenes que aquí interesan no son hechos aislados, sino resultado de un plan sistemático llevado a cabo por un aparato que puede ser del Estado.

El poder judicial ha sido marginado, en este caso, con la creación de dos sistemas penales paralelos: a) uno público encargado de las detenciones y juzgamientos cumplidas al margen del sistema penal formal, y b) otro subterráneo (organización criminal estatal) al que se encarga la sistemática práctica de esos crímenes (Zaffaroni, 2001, pp. 53 y 54.). Siguiendo este argumento es posible afirmar que este fenómeno puede verse con mayor evidencia en los crímenes que son objeto de la competencia de la cPl, en los que incluso pueden concurrir tales crímenes con episodios de agresión, confrontación, conflicto armado interno $u$ otros.

Sencillamente, como lo señala Zaffaroni (2001, pp. 53-59), este episodio pudo verse en las dictaduras regionales de Latinoamérica, y para adicionar este concepto, también se puede advertir en la compleja situación de violencia política de Colombia. Sobre este aspecto, precisamente, en virtud del principio universal estos fenómenos de criminalidad sistemática han tenido como consecuencia internacional las causas abiertas en países europeos contra sus perpetradores, como por ejemplo, las condenas en Francia contra un oficial argentino en razón de la nacionalidad de las víctimas y, más recientemente, el señalamiento de la justicia italiana contra dos altos oficiales y algunos miembros de una policía fronteriza. (Cassese y Delmas, 2004, pp. 34 y 35).

Pues bien, atendiendo este desarrollo del principio universal, puede verse que en virtud de la CPI este cobra vigencia multilateral y ya no obedece a los principios de derecho interno de determinado país. En todo caso, este principio de jurisdicción universal comienza a perder impor- 
tancia en virtud del ER, toda vez que definitivamente la cPI define los problemas de limitación de la justicia universal que residían en campos que eran de menor recibo en razón de su falta de fuerza vinculante.

En este contexto, los criterios expresados obedecen a las fuentes del ER, con la diferencia de que en este último la competencia es de un organismo supranacional y no estatal. Así mismo, el concepto de la lesión de bienes jurídicos que interesan a la comunidad internacional constituye el fundamento más relevante de la jurisdicción universal concebida en el art. $1^{\circ} \mathrm{ER}, \mathrm{y}$ al mismo tiempo le confiere a la cPI la potestad de luchar en abstracto contra la impunidad en el plano internacional, bajo las condiciones que el ER establece para el ejercicio de su competencia.

\section{LA CONSTRUCCIÓN DE LA COMPE- TENCIA INTERNACIONAL EN LA CPI}

Una vez anotadas las bases que construyeron la justicia internacional, que se traduce en el camino hacia la institucionalización de la cPI, se observa, revisando nuevamente los antecedentes de la misma, que tras las atrocidades de la segunda guerra mundial, como lo manifiesta George Werle (2011, p. 37), representadas entre otras acciones en el genocidio de los judíos europeos, la opinión pública se vio conmovida una y otra vez por la comisión de crímenes de gran magnitud dirigidos o encubiertos por el Estado, pues faltó voluntad política para sancionar tales conductas.
De igual forma, tan solo con los hechos narrados de la ex-Yugoeslavia y Ruanda, las Naciones Unidas decidieron instaurar los tribunales internacionales ad hoc que permitieron reforzar la validez del derecho penal internacional, hecho que culmina sin duda con el Estatuto de la cPI que entró en vigencia en el 2002, como primera codificación comprensiva del derecho penal internacional. Esta institución permitió desde entonces instaurar un foro permanente de la justicia internacional que implica la responsabilidad procesal individual de aquellos que son convocados por la cPI (Werle, 2011, pp. 36 y 37).

En tal sentido, los esfuerzos de las Naciones Unidas en torno a la codificación de algunos crímenes derivados de las graves violaciones del DIH y de los precedentes de los tribunales analizados con anterioridad, dejando de lado la jurisdicción universal comentada en los apartes anteriores, en forma definitiva comenzó en 1946 y fue hasta 1996, y su alcance solo pudo ser asumido por un organismo de carácter internacional e independiente que, finalmente, terminó siendo constituido el 17 de julio de 1998: la Corte Penal Internacional. El camino hacia la competencia especial internacional en materia penal se desarrolló teniendo en cuenta los siguientes fundamentos.

\section{A. Principales elementos cronológicos en la formación de la CPI}

En efecto, en 1947 la Asamblea General de Naciones Unidas ordenó al Comité de Codificación del Derecho Internacional formular una codificación general de las ofensas contra la paz y la 
seguridad de la humanidad, así como también promulgar los principios de derecho internacional reconocidos en la Carta del Tribunal de Nüremberg y en la jurisprudencia y el tribunal. El 9 de diciembre de 1948, con ocasión de la adopción por parte de la Asamblea General de las Naciones Unidas de la Convención sobre la prevención y castigo del crimen de genocidio, los miembros piden a la Comisión de Derecho Internacional (International Law Comisión -ILC) estudiar la posibilidad de establecer una corte penal internacional (Bassiouni, 1999, pp. 89-90).

En 1950, el relator designado para elaborar un código especial de ofensas en contra de la humanidad entregó un informe que proponía un código penal sustantivo y un estatuto para una corte penal internacional, pese a la disparidad de criterios debidos a la guerra fría entre las dos potencias sobresalientes de entonces (Rusia y Estados Unidos). Francia era el único miembro permanente del Consejo de Seguridad dispuesto a apoyar la propuesta. Más tarde, en 1951, fue creado un comité especial de la Asamblea General, compuesto por representantes de 17 Estados, con el propósito de redactar una Convención para la creación de una corte penal internacional, sin embargo las grandes potencias no dieron apoyo al proyecto porque era políticamente prematuro y la revisión culminó en 1953. De todos modos, el estatuto para una corte penal internacional fue postergado en dicha ocasión, luego de que concluyera la preparación del proyecto de código de ofensas, el cual contenía cinco artículos y una lista de trece crímenes internacionales (Bassiouni, 1999, p. 92).
El instrumento mencionado fue entregado a la Asamblea General en 1954; en él se menciona a la agresión (art. $2^{\circ}$ ) a partir de los conceptos de otro comité que fue constituido para tal fin. Los dos proyectos, el de la corte penal internacional y el código de ofensas fueron puestos a un lado mientras se desarrollaron las definiciones de los delitos y de las medidas, proceso que duró varias décadas. Entre 1954 y 1974 se nombraron cuatro comités para definir la agresión, los cuales se conformaron sucesivamente de quince miembros hasta un número especial de 35 delegados, hecho que se consolidó en el año de 1974. Finalmente, la Asamblea General adoptó la pretendida definición, a través de una resolución de consenso, luego de casi veinte años de deliberaciones, sin embargo, el texto no fue adoptado en ningún instrumento de carácter multilateral (Bassiouni, 1999, pp. 93 y 94).

En el año de 1981, la Asamblea General solicitó reconsiderar los proyectos del estatuto de la corte penal internacional y el del código de ofensas. Para el año siguiente el nuevo relator designado elaboró un informe que contenía algunas consideraciones generales sobre derecho penal internacional, responsabilidad estatal y personal, así como las observaciones sobre el contenido de una legislación semejante. Fruto de esta labor, en 1991 se terminó el primer texto que luego de su revisión se adoptó en 1996 (Bassiouni, 1999, pp. 93 y 94).

De igual forma, a raíz de los sucesos de 1989 que motivaron el fin de la guerra fría junto con el incremento de un número dramático de sucesos y operaciones de las Naciones Unidas en 
favor del mantenimiento de la paz, así como los desarrollos del comité de expertos de una onG, los cuales fueron tomados como preparatorios en el Octavo Congreso de la Organización Internacional sobre Prevención del Crimen y el Tratamiento de Acusados, propiciaron revivir la idea de la necesidad de la creación de la corte penal internacional (Guerra, 2001, p. 3).

Simultáneo al desarrollo de las iniciativas consolidadas tanto en el proyecto de la corte penal internacional como en el proyecto de código de crímenes de guerra, incidieron principalmente en el impulso de la propuesta los sucesos ocurridos en 1992 en Bosnia-Herzegovina y en Ruanda (ya reseñados), que motivaron el establecimiento de los Tribunales ad-hoc para la antigua Yugoeslavia en 1993 y en 1994, todo ello con el fin de hacer justicia ante los graves atentados de genocidio en contra de los habitantes de dichas naciones.

Finalmente, luego de varios informes, se llegó al acuerdo de someter la propuesta a discusión en la Asamblea General de las Naciones Unidas a más tardar en 1998, año en el cual se produjo su aprobación definitiva por medio del Estatuto de Roma, instrumento constitutivo de la Corte Penal Internacional, y que introdujo muchas variables en el plano internacional, dadas las características del tratado, así como en materia de derecho penal ante la fusión de múltiples instituciones provenientes del derecho continental y del derecho anglosajón, por supuesto, con las consecuencias finales en los principios generales del Estatuto.

\section{B. Desarrollo de la CPI en el derecho interno. Del proyecto de acto legislativo 02 de 2001 a la Ley 742 del 5 de junio de 2002}

La adopción y ratificación del ER en la legislación interna de nuestro país se logró después de intensos debates en dos legislaturas. Luego de los ocho debates reglamentarios se pudo obtener como resultado una cláusula abierta a la interpretación, la cual si bien no definió la razón para ratificar el ER aportó las primeras bases de acierto para su eficaz integración en nuestro sistema jurídico. A partir de la interpretación de esta nueva cláusula que hace parte de nuestro ordenamiento constitucional se puso en marcha el proyecto de ley, mecanismo final de ratificación del ER.

A grandes rasgos, este fue el panorama de incorporación del que inicialmente se denominó Proyecto de Acto Legislativo $n^{\circ}$. 014, el cual luego de su discusión y aprobación final fue sancionado como Acto Legislativo $\mathrm{n}^{\circ}$. 02 de 27 de diciembre de 2001, por medio del cual se modifica el artículo 93 de la Constitución Política de Colombia.

El texto definitivo del Acto Legislativo es el siguiente:

Artículo $1^{\circ}$. Adiciónese el artículo 93 de la Constitución Política con el siguiente texto:

El Estado Colombiano puede reconocer la jurisdicción de la Corte Penal Internacional en los términos previstos en el Estatuto de Roma adoptado el 17 de julio de 1998 por la Con- 
ferencia de Plenipotenciarios de las Naciones Unidas y, consecuentemente, ratificar este tratado de conformidad con el procedimiento establecido en esta Constitución.

La admisión de un tratamiento diferente en materias sustanciales por parte del Estatuto de Roma con respecto a las garantías contenidas en la Constitución tendrá efectos exclusivamente dentro del ámbito de la materia regulada en él.

Artículo $2^{\circ}$. El presente acto legislativo rige a partir de su promulgación.

(Congreso de la República, 2001, p. 2).

Según la publicación efectuada en el Diario Oficial n. 44826 del 7 de junio de 2002, el Gobierno Nacional sancionó la Ley 742 el 5 de junio de 2002 mediante la cual "se aprueba el Estatuto de Roma de la Corte Penal Internacional". De acuerdo con las disposiciones consagradas en la Constitución Política, la Ley fue remitida de inmediato a la Corte Constitucional para su revisión de constitucionalidad. En debate adelantado sobre el particular, en el Tribunal referido la mayoría de instituciones coincidieron en expresar el cumplimiento de la Ley 742 de 2002 de los requisitos establecidos en la Constitución respecto de las normas aprobatorias de tratados. En igual sentido, afirmaron que concordaba con lo prescrito en los artículos 226 y 227 relativos a los principios que guían a Colombia en materia de relaciones internacionales (Sandoval, 2003).

Además, la mayoría de instituciones estatales, al igual que la Corte, expresaron que la constitu- cionalidad de dicha Ley se debía principalmente a su antecedente, el Acto Legislativo 02, y a la inclusión de la cláusula específica respecto del ámbito de competencia del instrumento internacional. La Corte acogió todos estos conceptos en su providencia del 30 de julio de 2002, donde declara la exequibilidad del Estatuto de Roma frente a la Constitución colombiana y reitera la conformidad con la normatividad interna de nuestro país de la Ley 742 de 2002, es decir, la ley aprobatoria del Tratado (Corte Constitucional. Sentencia C-578 de 2002).

La Corte Constitucional, además de reiterar en su providencia el señalamiento referido a la posibilidad constitucional que otorgó el Acto Legislativo 02 de 2001, al incluir en el artículo 93 de la Constitución Política la facultad para aprobar el Estatuto de Roma, estableció una cláusula especial según la cual, para todos los efectos, los aspectos controvertidos del Estatuto de Roma, examinados con anterioridad, se entenderán únicamente bajo el ámbito de la competencia regulada en él y no dentro del ámbito de los que traten materias similares en el capítulo de derechos fundamentales de la Constitución. Por el contrario, estos se entenderán ampliados en atención a dicho concepto (Corte Constitucional. Sentencia C-578 de 2002).

Finalmente, mediante la Ley 1268 de 31 de diciembre de 2008, fueron aprobadas las reglas de procedimiento y prueba y los elementos de los crímenes de la Corte Penal Internacional, es decir, tienen plena vigencia en la actualidad en el derecho interno, con las consecuencias que dicha normativa genera. Con fundamento en 
las anteriores consideraciones y atendiendo las precisiones anotadas, la Corte Constitucional declaró la exequibilidad tanto del tratado examinado como de la Ley 742 del 5 de junio de 2002 "Por medio de la cual se aprueba el Estatuto de Roma de la Corte Penal Internacional, hecho en Roma el día diecisiete (17) de julio de mil novecientos noventa y ocho (1998)". El Gobierno Nacional, finalmente, el 5 de agosto de 2002 cumplió con el canje de notas con las Naciones Unidas, declarando la ratificación del Estatuto de Roma con el uso de la cláusula descrita en el artículo 124, examinado con anterioridad, y con ello entraron en vigor en el derecho interno los instrumentos objeto de estudio en el presente trabajo.

Como se indicó anteriormente, esta cláusula dejó de tener efectos el día $1^{\circ}$ de noviembre de 2009 al cumplirse los siete años fijados para su establecimiento con respecto a los crímenes de guerra. En consecuencia, en la actualidad rigen para Colombia todos los crímenes comprendidos en el artículo $5^{\circ}$ del Estatuto de Roma, lo que se denomina vigencia en pleno de la Corte Penal Internacional.

Así mismo, resulta necesario reiterar que precisamente a través de dicho examen comienza a perfilarse la forma de adaptación de los diferentes condicionamientos de la jurisdicción universal del ER en el derecho interno, así como su forma de intervención y competencia en la jurisdicción nacional, aspectos que se analizan en el siguiente punto.

\section{FACTORES DE COMPETENCIA DEL ESTATUTO DE ROMA Y A DMISIBILIDAD}

Luego del recorrido histórico anterior se observa que, en último término, el alcance del Estatuto de Roma se ha clasificado en los factores ratione temporis, ratione paersonae y ratione materiae, que presentan los siguientes elementos:

\section{A. Factor ratione temporis}

Hace relación a los condicionamientos y situaciones concretas que se deben analizar frente a elementos de tiempo, es decir, cuándo se puede ejercer la competencia de la Corte Penal Internacional. En este sentido, la cPI empieza a tener conocimiento de crímenes después de su entrada en vigencia (art. 11 ER) y conforme al art. 29 del ER estos no prescribirán, todo ello con apoyo en el artículo 24.1 que señala expresamente: "Nadie será personalmente responsable de conformidad con el presente Estatuto por una conducta anterior a su entrada en vigencia". Es decir que en el caso colombiano la competencia de la cPI, por el factor ratione temporis, comenzó a operar el $1^{\circ}$ de noviembre de 2002, fecha de su entrada en vigencia en el sistema nacional; $y$ el $1^{\circ}$ de noviembre de 2009 para el caso de los crímenes de guerra, debido a la cláusula transicional acogida en el año 2002. Anello (2003, p. 46) sostiene que si bien es cierto estas condiciones rigen en un Estado parte cuando el ER ha entrado en vigencia en su sistema jurídico y, en consecuencia, podrá ejercer la competencia sobre sus nacionales y en su territorio por críme- 
nes cometidos únicamente desde la entrada en vigor para dicho Estado, es posible que un Estado consienta que la cPI puede ejercer tal competencia a partir del $1^{\circ}$ de julio de 2002.

Esto es, se pueden hacer retroactivos sus efectos con respecto a su entrada en vigor en un Estado determinado, pero más allá de los límites de vigencia del ER en ningún caso. Por ende, en Colombia las posturas que toman como base el Estatuto de Roma para hechos ocurridos antes del $1^{\circ}$ de noviembre de 2002, fecha en que entró en vigencia en nuestro país, no tienen ningún soporte jurídico viable. En el mismo sentido es necesario interpretar la cláusula transicional del art. 124 a la cual se acogió el Estado colombiano al momento de ratificar el tratado (depósito de instrumentos): los crímenes de guerra solo rigen en nuestro sistema a partir del $1^{\circ}$ de noviembre de 2009, fecha de vencimiento de la declaración mencionada.

De otra parte, los extremos citados indican la ratificación de los principios de vigencia de la ley e irretroactividad de la ley penal, conforme a las prescripciones del principio de legalidad interno (art. 6, Código Penal colombiano), y de igual forma plantean los extremos de la prescripción que en el derecho interno fueron analizados en la sentencia C- 578 de 2002, que examinó la ley aprobatoria del tratado en cuestión.

\section{B. Factor ratione personae. Subjetivo}

Se refiere a las personas sobre las cuales la CPI podrá ejercer su competencia, esto es, personas físicas mayores de 18 años (art. 26 ER), por conductas posteriores a la entrada en vigor del Estatuto (art. 24 ER), sin distinción alguna basada en el cargo oficial (art. 27 ER). Será penalmente responsable por estas conductas quien: cometa la conducta por sí solo, con otro o por conducto de otro; las ordene, proponga o induzca, se hayan consumado o hayan quedado en grado de tentativa; con el propósito de facilitar la comisión del crimen sea cómplice, encubridor o colaborador, incluso suministrando los medios o contribuyendo de algún modo en la comisión o tentativa de comisión del crimen por un grupo de personas que tengan una finalidad común (art. 25.3 ER).

Por otra parte, en el caso del delito de genocidio, la instigación ha de ser directa y pública (art. 25 ER); así mismo, los jefes militares serán penalmente responsables de los crímenes de competencia de la Corte cuando hubieren sido cometidos por fuerzas bajo su mando y control efectivo (art. 28 ER).

De acuerdo con las anteriores previsiones, se encuentran excluidas de la competencia de la CPI solamente las personas menores de 18 años (art. 26 ER); las que padezcan enfermedad o deficiencia mental que les impida apreciar la ilicitud de su conducta o la capacidad para controlar su comportamiento; aquellas que se encuentren en estado de intoxicación que las prive de la misma capacidad, salvo que se hubieren intoxicado voluntariamente; quienes hayan actuado en estado de defensa propia razonable; en estado de defensa de un bien esencial para la supervivencia o que hubieren cometido uno de los crímenes de competencia de la Corte 
como consecuencia de coacción dimanante de amenazas inminentes de muerte o lesiones graves (art. $31 \mathrm{ER}$ ); igualmente, las personas que se encuentren en error de hecho y de derecho que hagan desaparecer el elemento de intencionalidad (art. 32 ER).

\section{Factor ratione materiae. Los crímenes de competencia de la CPI}

Se refiere a los crímenes de competencia del máximo Tribunal Penal Internacional adoptado por la comunidad de naciones. En este ámbito, la naturaleza de las conductas desarrollan el principio de persecución de crímenes internacionales, que tiene una expansión inusitada no solo por las corrientes derivadas de los instrumentos internacionales de protección de derechos humanos o de los instrumentos creados para la persecución de amenazas globales (terrorismo, delincuencia organizada, drogas, etc.), sino también por los precedentes emanados de los tribunales ad hoc de la posguerra (Nüremberg y Tokio) que sentaron las bases de la competencia internacional comprendida en el ER de 1998. En tales instancias se asegura el modelo de jurisdicción internacional, la represión de los principales crímenes internacionales, así como los principios del juicio en actuaciones de tal naturaleza; ambos tribunales han sido objeto de diversas críticas. Para Anello (2003, pp. 21 y 22) el principal reproche se relaciona con su establecimiento, ya que por tratarse de jurisdicciones creadas por los vencedores del conflicto para juzgar los crímenes de las potencias vencidas, solo representaron una parte de la comunidad internacional. En términos jurídicos se po- dría decir que estos no respetaron los principios de imparcialidad y objetividad del debido proceso ni el de legalidad, sin embargo, cualquiera que sea la crítica, Naciones Unidas legitimó los principios de Nüremberg (Resolución 95 (I) de 23 de octubre de 1946).

En igual medida es preciso citar la doctrina internacional sentada posteriormente en los tribunales ad hoc contemporáneos que en Yugoeslavia y Ruanda dieron amplitud a la persecución y definición de los contextos necesarios para la comisión de crímenes de genocidio, lesa humanidad y crímenes de guerra, así como a la consideración de conductas punibles en el escenario de conflicto armado interno e internacional (Anello, 2003, pp. 23 y 24).

Así, siguiendo el criterio de la Corte Constitucional colombiana, un Estado, al aceptar ser miembro del ER reconoce sin más requisitos la jurisdicción de la cPI respecto de los crímenes estipulados en el artículo $5^{\circ}$, que corresponden a las siguientes denominaciones:

\section{Genocidio}

Entendido como cualquier acto con la intención de destruir total o parcialmente a un grupo nacional, étnico, racial o religioso como tal. Requiere unos elementos comunes o de contexto para la configuración de las modalidades descritas en el ER artículo $6^{3}$, que son:

3 "Artículo 6. Genocidio: A los efectos del presente Estatuto, se entenderá por "genocidio" cualquiera de los actos mencionados a continuación, perpetrados con la intención de destruir total o parcialmente a un grupo nacional, étnico, racial o religioso como tal: a) Matanza de miembros del grupo; b) Lesión grave a la integridad física o mental 
- Que la conducta se realice sobre un grupo nacional, étnico, racial o religioso determinado.

- Que el autor haya tenido la intención de destruir, total o parcialmente, a ese grupo nacional, étnico, racial o religioso como tal.

- Que la conducta haya tenido lugar en el contexto de una pauta manifiesta de conducta similar, dirigida contra ese grupo o haya podido por sí misma causar esa destrucción. En el derecho interno aparece: identidad con los tipos descritos en los art. 101 y 102 - Apología del genocidio y genocidio que adicionalmente incluye el genocidio político.

\section{Crímenes de lesa humanidad}

Cualquiera de los actos relacionados en el ER de 1998, artículo 7, cuando se cometan como parte de un ataque generalizado o sistemático contra una población civil y con conocimiento de dicho ataque. Requiere de unos elementos comunes para la configuración de las modalidades allí descritas ${ }^{4}$, como son:

de los miembros del grupo; c) Sometimiento intencional del grupo a condiciones de existencia que hayan de acarrear su destrucción física, total o parcial; d) Medidas destinadas a impedir nacimientos en el seno del grupo; e) Traslado por la fuerza de niños del grupo a otro grupo".

$4 \quad$ Las modalidades descritas en el artículo $7^{\circ}$ del ER de 1998 son las siguientes: a) Asesinato; b) Exterminio; c) Esclavitud; d) Deportación o traslado forzoso de población; e) Encarcelación u otra privación grave de libertad física en violación de normas fundamentales de derecho internacional; f) Tortura; g) Violación, esclavitud sexual, prostitución forzada, embarazo forzado, esterilización forzada u otros abusos sexuales de gravedad comparable; h) Persecución de un grupo o colectividad con identidad propia fundada en motivos políticos, raciales, nacionales, étnicos, culturales, religiosos, de género u otros motivos universalmente reconocidos como inaceptables con arreglo al derecho internacional, en conexión con cualquier acto mencionado en el presente párrafo o con cualquier crimen de la competencia de la Corte; i) Desaparición forzada de personas; j) El crimen de apartheid; k) Otros actos inhumanos de carácter similar que causen intencionadamente
- Que la conducta haya tenido lugar como parte de un ataque generalizado o sistemático dirigido contra una población civil.

- Que el autor haya tenido conocimiento de que la conducta era parte de un ataque generalizado o sistemático dirigido contra una población civil o haya tenido la intención de que la conducta fuera parte de un ataque de ese tipo.

Esta clase de crímenes, desde la adopción del ER han causado controversia por la ausencia de base legal interna en Colombia, sin embargo para la competencia de la cPI esto no es inconveniente como se verá más adelante, de acuerdo con el sistema de fuentes del instrumento analizado que privilegia para tales efectos las cláusulas desarrolladas en el tratado y no en la ley interna.

\section{Crímenes de guerra}

La cPI tendrá competencia respecto de los crímenes de guerra en particular cuando se cometan como parte de un plan o política o como parte de la comisión en gran escala de tales crímenes, conforme a las modalidades establecidas en el artículo 8 del ER de $1998^{5}$. Los elementos

grandes sufrimientos o atenten gravemente contra la integridad física o la salud mental o física.

5 Artículo 8. Crímenes de guerra. 1. La Corte tendrá competencia respecto de los crímenes de guerra en particular cuando se cometan como parte de un plan o política o como parte de la comisión en gran escala de tales crímenes.

2. A los efectos del presente Estatuto, se entiende por "crímenes de guerra": Literales a al f.

a) Infracciones graves de los Convenios de Ginebra de 12 de agosto de 1949 , a saber, cualquiera de los siguientes actos contra personas o 
comunes de esta tipología, complementados en los elementos del crimen son los siguientes:

- Que el autor haya dado muerte a una o más personas.

- Que esa persona o personas hayan estado protegidas en virtud de uno o varios de los Convenios de Ginebra de 1949.

- Que el autor haya conocido las circunstancias de hecho que establecían esa protección.

- Que la conducta haya tenido lugar en el contexto de un conflicto armado internacional y haya estado relacionada con él.

bienes protegidos por las disposiciones del Convenio de Ginebra pertinente.

b) Otras violaciones graves de las leyes y usos aplicables en los conflictos armados internacionales dentro del marco establecido de derecho internacional.

c) En caso de conflicto armado que no sea de índole internacional, las violaciones graves del artículo 3 común a los cuatro Convenios de Ginebra de 12 de agosto de 1949, a saber, cualquiera de los siguientes actos cometidos contra personas que no participen directamente en las hostilidades, incluidos los miembros de las fuerzas armadas que hayan depuesto las armas y las personas puestas fuera de combate por enfermedad, herida, detención o por cualquier otra causa.

d) El párrafo $2 \mathrm{c}$ ) del presente artículo se aplica a los conflictos armados que no son de índole internacional, y por consiguiente, no se aplica a las situaciones de tensiones internas y de disturbios interiores, tales como los motines, los actos esporádicos y aislados de violencia u otros actos análogos.

e) Otras violaciones graves de las leyes y los usos aplicables en los conflictos armados que no sean de índole internacional, dentro del marco establecido de derecho internacional.

f) El párrafo 2 e) del presente artículo se aplica a los conflictos armados que no son de índole internacional, y, por consiguiente, no se aplica a las situaciones de tensiones internas y de disturbios interiores, tales como los motines, los actos esporádicos y aislados de violencia u otros actos análogos. Se aplica a los conflictos armados que tienen lugar en el territorio de un Estado cuando existe un conflicto armado prolongado entre las autoridades gubernamentales y grupos armados organizados o entre tales grupos.

3. Nada de lo dispuesto en los párrafos 2 c) y e) afectará a la responsabilidad que incumbe a todo gobierno de mantener o restablecer el orden público en el Estado o de defender la unidad e integridad territorial del Estado por cualquier medio legítimo.
- Que el autor haya tenido conocimiento de que había circunstancias de hecho que establecían la existencia de un conflicto armado.

En el caso colombiano la dificultad para determinar el contexto de los crímenes advertidos es una prevención que puede establecerse tanto a nivel judicial como político, dados los innumerables elementos que incluso tienen una base legal nacional, como la Ley de Justicia y Paz o el marco jurídico para la paz, entre otros.

\section{De agresión}

Una vez se cumplan los requisitos de su definición desarrollados en la Asamblea de Estados Parte de 2010.

Pues bien, analizados los elementos correspondientes a la configuración de los crímenes es preciso declarar que el Estado parte acepta automáticamente la competencia de la cPI sobre estas conductas y las personas que incurran en ellas, a partir del día de la entrada en vigor del Estatuto, conforme al artículo 11 ER. En el caso particular de Colombia ver Corte Constitucional, sentencia C-578 de 2002.

Desde este aspecto procesal, la cPI también será competente cuando de conformidad con el párrafo 2 del Estatuto sea necesaria la aceptación de un Estado que no sea Parte, respecto de crímenes particulares cometidos dentro de su territorio o por sus nacionales. En esta situación se requiere que dicho Estado exprese el consentimiento por medio de una declaración depositada en poder del Secretario (artículo 12.3 ER). 
Igualmente lo será cuando el Consejo de Seguridad le remita un asunto, actuando con arreglo al capítulo VII de la Carta de Naciones Unidas (artículo 13 ER).

Una vez analizado este aspecto de admisibilidad y las condiciones en que es viable la ruptura de la cosa juzgada, se puede proceder a la activación de la jurisdicción complementaria a nivel interno.

\section{LOS FACTORES CONCRETOS EN LA SITUACIÓN COLOMBIANA}

En síntesis, en las tres situaciones objeto de estudio es imprescindible dilucidar el alcance en el derecho interno de los diversos factores que intervienen en la competencia de la cPI y sus consecuencias tanto sustanciales como procesales.

En las sustanciales es indispensable analizar la trascendencia de las conductas objeto de competencia, y en el ámbito procesal todos los elementos necesarios para determinar los posibles autores, el alcance territorial, los factores probatorios y de cooperación judicial, el efecto de la extradición, la entrega, el intercambio probatorio, etc., todo ello dentro de la esfera de la competencia pretendida.

En este sentido se derivan varias consecuencias dependiendo de si el Estado es signatario del ER O acepta la competencia de este sin ser firmante de dicho Estatuto. En los dos casos es viable la competencia de la cPI si el crimen se presenta en el territorio, aeronave, buque, etc., o por la nacionalidad del acusado del crimen. Como ejemplo se puede citar el caso de Costa de Marfil, Estado que no había ratificado el ER y, por tanto, no era Parte en el 2003, año en que se inició el examen preliminar de los asuntos denunciados por dicho país (Coalición por la Corte Penal Internacional, s. f.). Sin embargo el mismo gobierno autorizó el ejercicio de las condiciones previas para tal efecto, de conformidad con el art. 12(3) ER, y en consecuencia la investigación en octubre de 2011 (Corte Penal Internacional, 3 octubre, 2011).

En el caso de la situación colombiana bajo examen de la CPI no hay discusión, pues Colombia es Estado parte desde noviembre de 2002 y las diferentes denuncias presentadas ante este organismo han promovido la actuación del Fiscal conforme al art. $12(1,2$,$) del ER; en el momento$ dicha oficina analiza si se cumplen las condiciones para ejercer la competencia de la Corte, conforme a los arts. 13 (c) y 15 ER. Actualmente la situación colombiana se encuentra bajo el examen preliminar, conforme a los informes rendidos en noviembre de 2011 y noviembre de 2012 respectivamente (Corte Penal Internacional, noviembre 2011 y 2012).

En segundo término, también puede ser ejercida la competencia mediante la remisión de un Estado Parte al Fiscal de la cPI, de una situación en la que parezca haberse cometido uno de los delitos de su ámbito de conocimiento; por remisión del Consejo de Seguridad como en el caso de Libia o de oficio por parte del Fiscal de la CPI, como en el caso de Kenia (Corte Penal Internacional, 2012). 
Por otra parte, la inadmisibilidad de un asunto por parte de la CPI está determinada en el artículo 17 del ER. En las cuestiones allí relacionadas se advierten las siguientes consecuencias que deben ser analizadas para saber si estas contienen el alcance del factor generador de impunidad en el derecho interno para ameritar la competencia suplementaria de la cPI.

En primer lugar es necesario tener en cuenta el valor de los fallos internos, que constituye uno de los primeros aspectos de la competencia de la $\mathrm{CPI}$. Al respecto es preciso mencionar, inicialmente, que tal y como lo expuso la Corte Constitucional en la sentencia C-578 de 2002, de conformidad con el artículo 20 del ER las decisiones de derecho interno sobre condena o absolución por alguno de los crímenes de la competencia del organismo internacional, en principio, hacen tránsito a cosa juzgada y, por lo tanto, nadie podrá ser enjuiciado de nuevo por los mismos hechos respecto de los cuales hubo pronunciamiento, ni por la Corte Penal Internacional ni por otro juez (artículo 20, numerales 1 y 2, ER).

De los diversos hechos generales que se mencionan en el contexto histórico de la primera parte resultaría necesario, en primer lugar, trazar la línea de tiempo del ER en Colombia para verificar la vigencia del Estatuto y, consecuentemente, realizar el seguimiento judicial respectivo para ver si en realidad han existido medidas judiciales efectivas para la cabal represión y reparación frente a las víctimas, desde el $1^{\circ}$ de noviembre de 2002 para el caso de crímenes de lesa humanidad o genocidio, y a partir del $1^{\circ}$ de noviembre de 2009 para los crímenes de guerra.
Al respecto es necesario tener en cuenta que si en la jurisdicción interna existe cosa juzgada sobre el asunto denunciado ante la cPI, y tal circunstancia se debió al propósito de sustraer al responsable de la competencia de la Corte (artículo 17. 1, literal C ER en concordancia con el artículo 20.3 ER) mediante un proceso que fue aparente, o por un procedimiento interno adelantado por un tribunal que no cumple con los requisitos de imparcialidad e independencia, y que se determine "bajo las circunstancias" que actuó de manera inconsistente con el deber de traer a la persona ante la justicia, el organismo internacional podrá ejercer su jurisdicción sobre dicho asunto y declarar la admisibilidad del caso (Corte Constitucional, sentencia C-578 de 2002).

En el contexto nacional, frente a este punto es relevante observar los períodos de justicia efectiva en los casos bajo examen de la justicia interna y si existieron posibles dilaciones que impidieron la actuación judicial. Por ejemplo, en los asuntos tratados por la Comisión de Acusaciones del Senado se revelan factores de ineficiencia en este sentido, sin embargo todo esto debe sujetarse también a la naturaleza de los crímenes, que según vimos deben ostentar la importancia internacional exigida para cada conducta de competencia de la cPI.

Sobre este particular, la Corte Constitucional (sentencia C-578 de 2002) reitera que este aspecto es de importancia en la medida en que la cPI puede ejercer su jurisdicción complementaria cuando el juicio nacional debió haberse realizado con el propósito de sustraer a una 
persona para que responda ante la justicia. Pero si la persona fue genuinamente enjuiciada por un tribunal independiente e imparcial, por ejemplo, cuando el proceso se adelanta con el fin de establecer la verdad de los hechos, hacer justicia efectiva y garantizar la reparación a las víctimas, la CPI no podrá ejercer su jurisdicción y deberá declarar que el asunto es inadmisible, de conformidad con lo que establece el artículo 20, numerales 1 y 2 del ER.

Al analizar el devenir de los acontecimientos en Colombia frente a los factores referidos, según Héctor Olásolo (2003, pp. 12 y 13) para los efectos de la competencia de la cPl es necesario advertir, en particular, las investigaciones sobre los paramilitares desmovilizados y tomar en cuenta los hechos a partir del año 2003, en virtud del denominado Pacto de Santa Fe de Ralito firmado el 15 de julio de 2003, y luego los pronunciamientos de la Corte Constitucional con ocasión de la Ley de Justicia y Paz -Ley 975 de 2006-.

Con respecto al texto Fiscalía de la Corte Penal Internacional. Report on the Preliminary Examination Activities, de 13 de diciembre de 2011 (supra n. ${ }^{0} 57$, párr. 85, p. 12.) el autor citado señala que en los exámenes preliminares se indicaba haber recibido 86 comunicaciones en relación con Colombia, de las cuales 17 se referían a hechos sobre los que la cPI no tenía jurisdicción; las otras 69 estaban siendo analizadas como parte del examen preliminar sobre Colombia que la Fiscalía desarrolla desde 2005. También se mencionan los principales actores involucrados en el conflicto de Colombia y los factores relacionados con la reducción del poder de los grupos paramilitares en los últimos años a través del proceso de desmovilización auspiciado por la Ley de Justicia y Paz; el que un cierto número de desmovilizados disidentes retomaban las armas en unidades de menor poder y control, así como el análisis de las cifras de los avances de las autoridades judiciales en materia de justicia (Olásolo, 2012, p. 12).

Además de tales avances, en el Reporte sobre el examen preliminar de actividades, publicado en noviembre de 2012 (pp. 28 a 38 y 29 a 48), aparece: 1) que la cPI determinó que la Oficina del Fiscal de dicho organismo internacional mantendrá el intercambio de comunicaciones con el Gobierno de Colombia en lo que respecta a las cuestiones relativas a los crímenes de lesa humanidad y de guerra bajo su competencia; 2) un examen detallado (punto 92 al 122) sobre las conductas y el contexto de lesa humanidad que involucra tanto a actores del conflicto como a fuerzas estatales; 3) un análisis del contexto de los crímenes de guerra que involucran a los actores del conflicto armado interno a partir del $1^{\circ}$ de noviembre de 2009 e igualmente si los grupos denominados bandas emergentes harían parte de dicho conflicto junto con sus conductas, aunque este último punto no está definido en la actualidad; 4) que la oficina del Fiscal General seguirá de cerca el Marco Legal para la Paz y su implementación, así como también buscará información adicional sobre la reforma del marco legislativo perteneciente a la jurisdicción penal militar; 5) que el examen preliminar de la situación en Colombia se centrará igualmente en: (i) el seguimiento del Régimen Jurí- 
dico para la Paz y otros desarrollos legislativos pertinentes, incluidos los aspectos jurisdiccionales en relación con la aparición de "nuevos grupos armados ilegales", (ii) los procedimientos en relación con la promoción y expansión de los grupos paramilitares, (iii) procedimientos relacionados con el desplazamiento forzado, (iv) los procedimientos relativos a los delitos de violencia sexual y (v) los casos de falsos positivos.

Es decir, en este último informe el examen ya profundiza tanto en las conductas como en los aspectos de competencia que podrían activarse en las situaciones especiales analizadas en el caso colombiano. Se destaca que todavía existe un nivel de confianza en la justicia nacional, que permite una nueva oportunidad para avanzar en los aspectos de impunidad sobre los cuales la cPI ha llamado la atención.

Lo relevante para este punto, de acuerdo con lo aquí tratado, es que los factores descritos -desde el aspecto territorial, de tiempo y del factor material objeto de persecución- aparecen configurados en el caso nacional, situación que implica que una vez superado el nivel de confirmación de los elementos examinados, la CPI analizará si los factores de justicia e impunidad tienen el umbral suficiente para poder asumirlos. Por ahora el sistema nacional solo está advertido sobre el examen preliminar que se viene haciendo a una situación colombiana; sin embargo, todavía es posible adoptar medidas internas para la eficaz represión de esta.
V. CONCLUSIONES

Los asuntos de competencia de la Corte Penal Internacional han tenido una construcción que deviene sin duda de los avances en los casos de Nüremberg y Tokio, en los que se afianzan los primeros conceptos de justicia internacional, conductas internacionales y juicio penal internacional.

La creación de la Corte Penal Internacional, como resultado de los precedentes mencionados y su configuración durante 50 años, arrojó como resultado no solo su adopción en Estados como el colombiano - proclive a aceptar su competencia en razón del conflicto nacional-, sino también la determinación de los asuntos de responsabilidad nacional que deben ser analizados desde una doble visión: las conductas tipificadas en el art. $5^{\circ}$ de la cPI y el desempeño de la justicia material colombiana que debe dar señales especiales de eficacia a fin de evitar niveles de impunidad que hagan necesaria la activación de la justicia internacional. Es en este sentido que se revela la responsabilidad del Estado colombiano frente a la competencia penal internacional.

\section{Bibliografía}

Anello, C. S. (2003). Corte Penal Internacional. Buenos Aires, Argentina: Universidad de Buenos Aires.

Bassiouni, M. Cherif. (Mayo de 1999.) Perspectivas extranjeras de Versalles a Ruanda en 75 
años: la necesidad de establecer una corte penal internacional permanente. Revista de Derecho Público, 10.

Cassese Antonio y Delmas-Marty Mireille (2004). Crímenes Internacionales y Jurisdicciones Internacionales. Grupo Editorial Norma, Bogotá, Colombia

Colombia. Congreso de la República. Acto legislativo $\mathrm{n}^{\circ}$. 02 de 27 de diciembre de 2001. Diario Oficial $n^{\circ} .44663$ del 31 de diciembre de 2001.

Colombia. Congreso de la República. (Diciembre 2008). Reglas de procedimiento y prueba del ER. Ley 1268 de 31 de diciembre de 2008. Diario Oficial $n^{\text {o. }} 47.219$ de 31 de diciembre de 2008.

Colombia. Corte Constitucional. Sentencia C-578-02 del 30 de julio de 2002.

Colombia. Oficina del Alto comisionado de las Naciones Unidas para los Derechos Humanos. (2004). Compilación de derecho internacional de los derechos humanos. Bogotá: Autor.

Colombia. Oficina del Alto Comisionado de las Naciones Unidas para los Derechos Humanos. (2002). Compilación de instrumentos internacionales. Derecho Internacional de los Derechos Humanos. Derecho Internacional Humanitario y Derecho Penal Internacional. Tercera Edición. Bogotá: Autor.
Córdoba Triviño, J. (2001). Derecho penal internacional. Estudio de los delitos de genocidio, de lesa humanidad y de los crímenes de guerra con referencia al nuevo Código Penal colombiano. Bogotá: Ediciones Jurídicas Gustavo Ibáñez Ltda.

Corte Penal Internacional. (2012). Informe exámenes preliminares Colombia. Recuperado de http://www.iccnow.org/documents/otp_-_ colombia_-_public_interim_report_-_november_2012.pdf.

Corte Penal Internacional. (Febrero 2011). Lybia Situation. Resolution 1970 2011. Adopted by the Security Council at its 6491st meeting. Recuperado de http://www.icc-cpi.int/ NR/rdonlyres/081A9013-B03D-4859-9D615D0B0F2F5EFA/0/1970Eng.pdf)

Corte Penal Internacional. (Noviembre 2011). Informe de examen preliminar Colombia. Recuperado de http://www.icc-cpi.int/NR/ rdonlyres/63682F4E-49C8-445D-8C13F310A4F3AEC2/284116/OTPReportonPreliminaryExaminations13December2011.pdf

Corte Penal Internacional. (Noviembre 2012). Informe de examen preliminar Colombia. Recuperado de http://www.iccnow.org/documents/otp_-_colombia_-_public_interim_report_-_november_2012.pdf

Corte Penal Internacional. (Noviembre 2012). Situation in Colombia. Interim Report. Recuperado de http://www.icc-cpi.int/en_menus/ icc/structure of the court/office of the prose- 
cutor/comm and ref/Pages/Situation-in-CoIombia-Interim-Report.aspx

Corte Penal Internacional. (Octubre 3 de 2011). Situation in the Republic of Cote D'ivoire. Recuperado de http://www.icc-cpi.int/iccdocs/ doc/doc1240553.pdf

Corte Penal Internacional. (s. f.). Situación Costa de Marfil. Recuperado de http://www.iccnow. org/?mod=ivorycoast,

Corte Penal Internacional. Casos y situación Libya. Recuperado de www.iccnow. org/?mod=libya

Guerra Lemoine, G. A. (2 de abril de 2001). Proyecto de Acto Legislativo $n^{\circ}$. 014. 2 de abril de 2001. Ponencia para primer debate. Colombia: Senado de la República.

Naciones Unidas. (2008). Resolución 95 (I) de la Asamblea General, de 23 de octubre de 1943. Afirmación de los principios de derecho internacional reconocidos por el Instituto del Tribual de Nuremberg. Recuperada de http:// untreaty.un.org/cod/avl/pdf/ha/ga_95-I/ ga_95-I_ph_s.pdf.

O'Donnell, D. (2004). Derecho internacional de los derechos humanos. Normativa, jurisprudencia y doctrina de los sistemas universal e interamericano. Bogotá: Oficina en Colombia del Alto Comisionado para los Derechos Humanos.

Olásolo Alonso, H. (2003). Corte Penal Internacional. ¿Dónde investigar? Especial referen- cia a la Fiscalía en el Proceso de Activación. Valencia, España: Tirant lo Blanch, Cruz Roja Española.

Olásolo Alonso, H. (Junio-diciembre 2012). El principio de complementariedad y las estrategias de actuación de la Corte Penal Internacional en la fase de examen preliminar. Lección inaugural del doctorado en Derecho, tercera corte del 26 de julio de 2012. Via Inveniendi et Iudicandi, 2(27). Recuperado de www.viei. usta.edu.co

Prosecutor v. Dusko Tadic. Trial Chamber. Case $\mathrm{n}^{\circ}$. IT-94-1-D (8 noviembre 1994). Case $\mathrm{n}^{\circ}$. IT-94-1-Tbis-R117 (11 noviembre 1999). Recuperado de http://www.icty.org/x/cases/tadic/tjug/en/tad-tsj991111e.pdf

Prosecutor v. Francis Kirimimuthaura, Uhuru Müigai Kenyatta and Mohammed Hussein Ali. (24 mayo 2012). Recuperado de http://www. iccnow.org/documents/Decision_on_the_ appeal_of_Mr_Francis_Kirimi_Muthaura.pdf.

Riedmatten, M. (2005). La jurisdicción universal: una breve introducción. Recuperado de http://www.cajpe.org.pe/RIJ/BASES/PID/Lju. htm

Sandoval Mesa, J. A. (2003). La incorporación de la Corte Penal Internacional. Análisis frente a la legislación Colombiana. Bogotá: Ediciones Nueva Jurídica.

Universidad Externado de Colombia. (1994). Colombia y el derecho internacional de los de- 
rechos humanos. Vol. II: obligaciones convencionales en materia de derecho internacional humanitario. Bogotá: Centro de Investigaciones y Proyectos Especiales.

Valencia Villa, A. (2003). Compilación de derecho penal internacional. Bogotá: Oficina del Alto Comisionado para las Naciones Unidas.
Werle, G. (2005). Tratado de derecho penal internacional. María del Mar Díaz Pita y otros (Trads.). Valencia, España: Tirant lo Blanch.

Werle, G. (2011). Tratado de derecho penal internacional. María Gutiérrez Rodríguez y otros (Trads.). $2^{\mathrm{a}}$ ed. Valencia, España: Tirant lo Blanch. 